\title{
Research Article \\ Role of Dielectric Constant on Ion Transport: Reformulated Arrhenius Equation
}

\author{
Shujahadeen B. Aziz \\ Advanced Polymeric Materials Research Laboratory, School of Science-Department of Physics, \\ Faculty of Science and Science Education, University of Sulaimani, Sulaimani, Kurdistan Region, Iraq
}

Correspondence should be addressed to Shujahadeen B. Aziz; shujaadeen78@yahoo.com

Received 20 January 2016; Accepted 10 April 2016

Academic Editor: Somchai Thongtem

Copyright (C) 2016 Shujahadeen B. Aziz. This is an open access article distributed under the Creative Commons Attribution License, which permits unrestricted use, distribution, and reproduction in any medium, provided the original work is properly cited.

Solid and nanocomposite polymer electrolytes based on chitosan have been prepared by solution cast technique. The XRD results reveal the occurrence of complexation between chitosan (CS) and the LiTf salt. The deconvolution of the diffractogram of nanocomposite solid polymer electrolytes demonstrates the increase of amorphous domain with increasing alumina content up to $4 \mathrm{wt} . \%$. Further incorporation of alumina nanoparticles (6 to $10 \mathrm{wt} . \% \mathrm{Al}_{2} \mathrm{O}_{3}$ ) results in crystallinity increase (large crystallite size). The morphological (SEM and EDX) analysis well supported the XRD results. Similar trends of DC conductivity and dielectric constant with $\mathrm{Al}_{2} \mathrm{O}_{3}$ concentration were explained. The TEM images were used to explain the phenomena of space charge and blocking effects. The reformulated Arrhenius equation $\left(\sigma_{\left(\varepsilon^{\prime}, T\right)}=\sigma_{o} \exp ^{\left(-E_{a} / K_{B} \varepsilon^{\prime} T\right)}\right)$ was proposed from the smooth exponential behavior of DC conductivity versus dielectric constant at different temperatures. The more linear behavior of DC conductivity versus $1000 /\left(\varepsilon^{\prime} \times T\right)$ reveals the crucial role of dielectric constant in Arrhenius equation. The drawbacks of Arrhenius equation can be understood from the less linear behavior of DC conductivity versus 1000/T. The relaxation processes have been interpreted in terms of Argand plots.

\section{Introduction}

Chitin, $\operatorname{poly}(\beta-(1 \rightarrow 4)-\mathrm{N}$-acetyl-D-glucosamine $)$, is a natural polysaccharide of major importance, first identified in 1884. This biopolymer is synthesized by an enormous number of living organisms; and considering the amount of chitin produced annually in the world, it is the most abundant polymer after cellulose [1]. On the other hand chitosan is a cationic polysaccharide, which contains $\beta$-1-4-linked 2amino-2 deoxy-D-glucopyranose repeat units and is readily obtained by alkaline N-acetylation of chitin [2]. Chitosan has great potential as a biomaterial because of [3] good biocompatibility, biodegradability, low toxicity, low cost [4], antimicrobial activity [5], hydrophilicity which certainly be of benefit to the fuel cell operation, and chemical and thermal stability at higher temperatures [6]. Thus chitosan has become of great interest not only as an underutilized resource but also as a new functional biomaterial of high potential in various fields [7]. The unique properties which separate chitosan from other biopolymers are the presence of amino groups [8] as depicted in Scheme 1(b).

Thus, the polycationic nature of chitosan due to the abundance of free amino $\left(\mathrm{NH}_{2}\right)$ groups (Scheme $1(\mathrm{~b})$ ) on the backbone of chitosan makes it possible to produce ionconducting polymer electrolyte [9]. This is related to the fact that the amine groups in chitosan structure can act as electron donors and interact with inorganic salts [10], and therefore chitosan meets an important requirement for acting as a polymer host for the solvation of salts [11]. One of the major reasons for poor ionic conductivity and concentration polarization has been attributed to the possibility of an ionassociation (ion-pairing) effect. This is due to weak dielectric permittivity of host polymers [12]. A number of approaches have been proposed to solve the state-of-the-art problems of ion-conducting polymers. Nanocomposite formation is the latest suggestion to overcome the disadvantages and improve the properties of SPEs; the method applied mostly is to disperse inorganic inert fillers in the SPE [13]. Electrical 


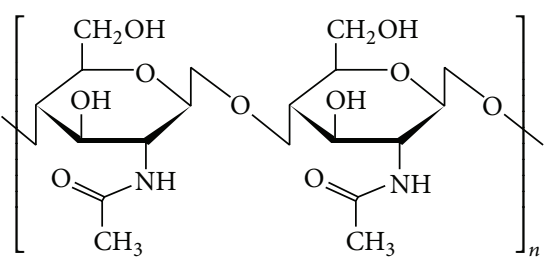

(a)

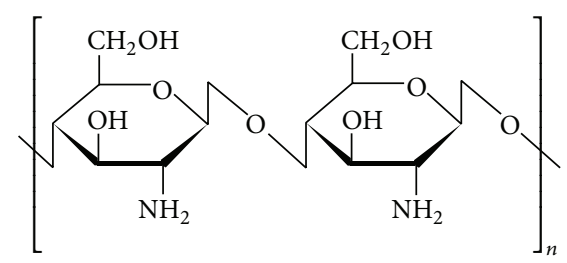

(b)

Scheme 1: Structure of (a) chitin and (b) chitosan [16].

properties such as dielectric permittivity can be suitably adjusted, simply by controlling the type and the amount of ceramic inclusions. Ceramic materials are typically brittle, possess low dielectric strength, and in many cases are difficult to be processed requiring high temperatures [14]. On the other hand, polymers possess relatively low dielectric permittivity; they can withstand high fields and are flexible and easy to process. By combining the advantages of both, one can fabricate new hybrid materials with high dielectric permittivity [15]. When these inorganic fillers are of nanodimensions, the composite polymer electrolyte formed is called nanocomposite polymer electrolyte (NCPE). But till now there is no fully satisfactory explanation available regarding the role played by these nanoparticles on DC conductivity [13]. Ion transport mechanism is a complicated subject in solid and nanocomposite polymer electrolytes. Thus the main objective of the present work is to show experimentally the crucial role of dielectric constant on cation transport mechanism and the necessary reformulation of Arrhenius equation.

\section{Experimental Details}

2.1. Raw Materials. Chitosan (CS) from crab shells ( $\geq 75 \%$ deacetylated, Sigma Aldrich), lithium triflate $\left(\mathrm{LiCF}_{3} \mathrm{SO}_{3}\right)$, and aluminum oxide $\left(\mathrm{Al}_{2} \mathrm{O}_{3}\right.$, size $\left.<50 \mathrm{~nm}\right)$ were supplied by sigma Aldrich. Acetic acid (1\%) was prepared using glacial acetic acid solution and used as the solvent in casting solid and nanocomposite polymer electrolytes.

2.2. Preparation of Solid and Nanocomposite Polymer Electrolytes. The SPE films were prepared by the solution cast technique. For this purpose $1 \mathrm{gm}$ of chitosan (CS) was dissolved in $100 \mathrm{~mL}$ of $1 \%$ acetic acid solution. The mixture was stirred continuously with a magnetic stirrer for several hours at room temperature until the chitosan powder has completely dissolved in the acetic acid solution. To this solution 10 wt.\% lithium triflate (LiTf) was added and the mixture was stirred continuously until homogeneous solution was obtained. The solution of CS : LiTf $(90: 10)$ was then cast into
TABLE 1: Composition of $(1-x)(0.9 \mathrm{CS}: 0.1 \mathrm{LiTf})-x \mathrm{Al}_{2} \mathrm{O}_{3}(0.02 \leq x \leq$ $0.1)$ NCPEs.

\begin{tabular}{lccc}
\hline Designation & CS : LiTf $=90: 10(\mathrm{~g})$ & $\mathrm{Al}_{2} \mathrm{O}_{3}(\mathrm{~g})$ & $\mathrm{Al}_{2} \mathrm{O}_{3}(\mathrm{wt} . \%)$ \\
\hline CSNC1 & 1.1111 & 0.0227 & 2.0 \\
CSNC2 & 1.1111 & 0.0463 & 4.0 \\
CSNC3 & 1.1111 & 0.0709 & 6.0 \\
CSNC4 & 1.1111 & 0.0966 & 8.0 \\
CSNC5 & 1.1111 & 0.1235 & 10 \\
\hline
\end{tabular}

CSNC1 to CSNC5 represent the sample code of $(1-x)(0.9$ CS: $0.1 \mathrm{LiTf})-$ $x \mathrm{Al}_{2} \mathrm{O}_{3}(0.02 \leq x \leq 0.1) \mathrm{NCPE}$ compositions.

clean and dry Petri dish and allowed to evaporate at room temperature to obtain a solvent-free film. To prepare NCPEs initially the chitosan and $\operatorname{LiTf}(90: 10)$ were dissolved in acetic acid to obtain homogeneous solutions as mentioned above. $\mathrm{Al}_{2} \mathrm{O}_{3}$ were first dispersed in $20 \mathrm{~mL}$ acetic acid solution and stirred. The $\mathrm{Al}_{2} \mathrm{O}_{3}$ concentrations were varied from $2 \mathrm{wt} \%$ to $10 \mathrm{wt} . \%$. The $\mathrm{Al}_{2} \mathrm{O}_{3}$ dispersoids were mixed with CS: LiTf $(90: 10)$ solutions and then continuously stirred. The solutions were then cast into different clean and dry Petri dish and allowed to evaporate at room temperature until solvent-free NCSPE films were obtained. The films were kept in desiccators with blue silica gel desiccant for further drying. Table 1 shows the codes and the concentration of the prepared nanocomposite solid polymer electrolytes (NCPEs).

2.3. XRD Investigation. In the present work, $\mathrm{XRD}$ used to reveal the structure of the prepared films; that is, they transferred to amorphous or crystalline after doping. XRD was carried out using a Siemens D5000 X-ray diffractometer with operating voltage and current of $40 \mathrm{kV}$ and $40 \mathrm{~mA}$, respectively. The wavelength of the monochromatic, X-ray beam is $1.5406 \mathrm{~A}^{\circ}$ and the glancing angles were in the range of $5^{\circ} \leq 2 \theta \leq 80^{\circ}$ with a step size of $0.1^{\circ}$.

2.4. Morphology Characterization. The combined usage of SEM-EDAX is an attempt to understand the structural and compositional complexity of the samples. A scanning electron micrograph (SEM) was taken using Leica 440 scanning electron microscope to study morphological appearance. The microscope was fitted with energy dispersive analysis of $\mathrm{X}$ rays (EDX), Oxford Instrument (LINK ISIS), to detect the overall chemical composition of NCSPE. Before observation, the NCSPE films were attached to aluminum holder using a conductive tape and then coated with a thin layer of gold.

2.5. Transmission Electron Microscopy (TEM). Transmission electron microscopy (TEM) images of the polymer electrolyte containing $\mathrm{Al}_{2} \mathrm{O}_{3}$ nanoparticle were recorded using a LEO LIBRA (accelerating voltage $120 \mathrm{kV}$ ) instrument. A drop of the solution of chitosan-silver triflate electrolyte was placed on a carbon coated copper grid and dried at room temperature after removal of excess solution using a filter paper.

2.6. Complex Impedance Spectroscopy Technique. Complex impedance spectroscopy gives information on electrical 
properties of materials and their interface with electronically conducting electrodes. The nanocomposite solid polymer electrolyte (NCSPE) films were cut into small discs $(2 \mathrm{~cm}$ diameter) and sandwiched between two stainless steel electrodes under spring pressure. The impedance of the films was measured in the frequency range from $50 \mathrm{~Hz}$ to $1000 \mathrm{kHz}$ using the HIOKI $3531 \mathrm{Z}$ Hi-tester which was interfaced to a computer. Measurements were also made at temperatures ranging between $303 \mathrm{~K}$ and $363 \mathrm{~K}$. The software controls the measurements and calculates the real $\left(Z^{\prime}\right)$ and imaginary $\left(Z^{\prime \prime}\right)$ parts of impedance. $Z^{\prime}$ and $Z^{\prime \prime}$ data were presented as a Nyquist plot and the bulk resistance was obtained from the intercept of the plot with the real impedance axis. The conductivity can be calculated from the following equation [17]:

$$
\sigma_{\mathrm{DC}}=\left(\frac{1}{R_{b}}\right) \times\left(\frac{t}{A}\right) .
$$

In (1), $t$ is the film's thickness and $A$ is its area.

The real $\left(Z^{\prime}\right)$ and imaginary $\left(Z^{\prime \prime}\right)$ parts of complex impedance $\left(Z^{*}\right)$ were also used for the evaluation of dielectric constant, the real $\left(M^{\prime}\right)$ part, and imaginary $\left(M^{\prime \prime}\right)$ part of complex electric modulus $\left(M^{*}\right)$ using the following equations $[18,19]$ :

$$
\begin{aligned}
\varepsilon^{\prime} & =\frac{Z_{i}}{\omega C_{o}\left(Z_{r}^{2}+Z_{i}^{2}\right)}, \\
M^{\prime} & =\omega C_{o} Z_{i}, \\
M^{\prime \prime} & =\omega C_{o} Z_{r} .
\end{aligned}
$$

Here $C_{o}$ is the vacuum capacitance and given by $\varepsilon_{o} A / t$, where $\varepsilon_{o}$ is a permittivity of free space and is equal to $8.85 \times$ $10^{-12} \mathrm{~F} / \mathrm{m}$. The angular frequency $\omega$ is equal to $\omega=2 \pi f$, where $f$ is the frequency of applied field.

\section{Results and Discussion}

3.1. XRD Analysis. In this study, $\mathrm{XRD}$ was performed to show the complex formation occurrence between $\mathrm{LiCF}_{3} \mathrm{SO}_{3}$ and chitosan. The diffractograms of the pure chitosan film and chitosan : $\operatorname{LiTf}(90: 10)$ complexes are illustrated in Figure 1. It can be seen that, with addition of lithium triflate (LiTf) into chitosan matrix, intensity of the crystalline peaks of pure chitosan decreased considerably (see Figure 1). This indicates the reduction in crystalline region of chitosan matrix. In other words with increasing salt concentration the amorphous domain of the chitosan electrolyte membrane increases. It is obvious that the peak of pure chitosan at $15.5^{\circ}$ shifted to $12.6^{\circ}$ in CS : LiTf systems. The effect of LiTf salt on crystal structure of chitosan can be seen elsewhere [20] in detail.

Figure 2 shows several crystalline peaks at around $32^{\circ}$, $34.4^{\circ}, 36^{\circ}, 39^{\circ}, 41^{\circ}, 45.7^{\circ}, 61^{\circ}$, and $67.1^{\circ}$ for pure $\mathrm{Al}_{2} \mathrm{O}_{3}$. The $\mathrm{X}$-ray diffraction pattern of the $\mathrm{Al}_{2} \mathrm{O}_{3}$ nanoparticles depicted in Figure 2 is very similar to the $\mathrm{Al}_{2} \mathrm{O}_{3}$ pattern reported in the literature [21]. It is obvious that the $\mathrm{Al}_{2} \mathrm{O}_{3}$ nanoparticles exhibit two sharp crystalline peaks at $45.7^{\circ}$ and $67.1^{\circ}$.

$\mathrm{X}$-ray diffraction analysis was performed to observe the effect of $\mathrm{Al}_{2} \mathrm{O}_{3}$ filler on the crystalline structure of CS : LiTf

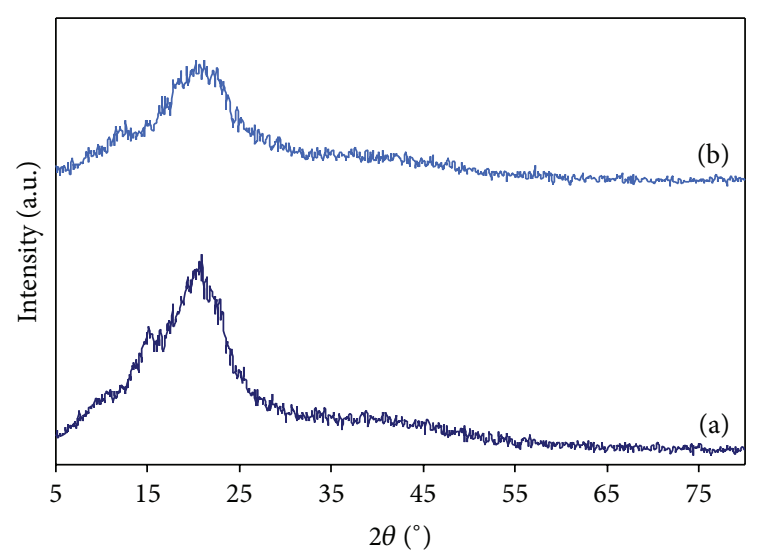

FIGURE 1: X-ray diffractogram of (a) pure chitosan (CS) and (b) chitosan: $\mathrm{LiCF}_{3} \mathrm{SO}_{3}(90: 10)$ system.

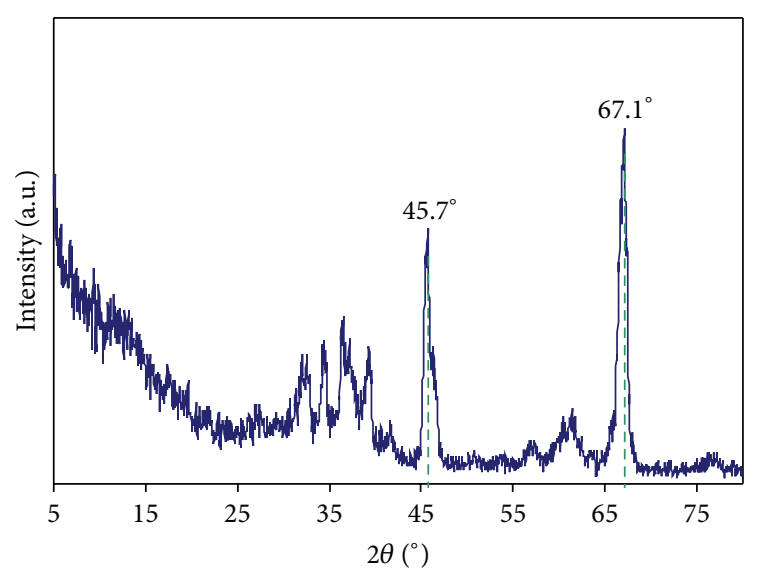

FIGURE 2: XRD patterns of pure $\mathrm{Al}_{2} \mathrm{O}_{3}$ nanoparticles.

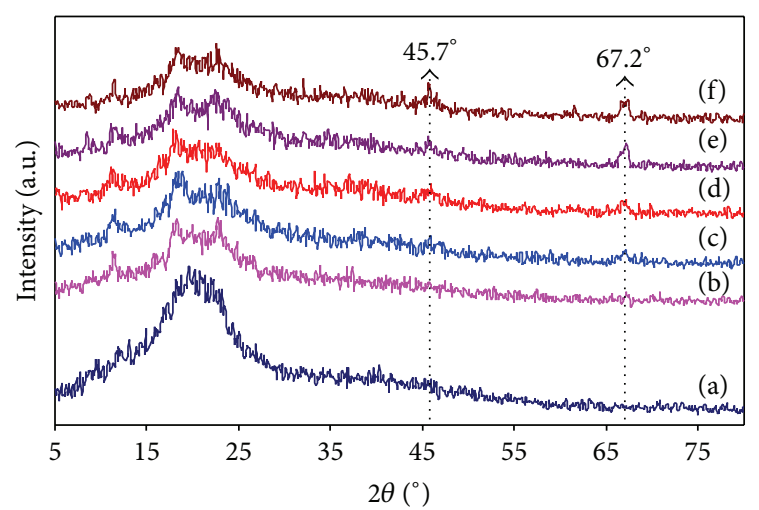

Figure 3: X-ray diffractogram of (a) CS : LiTf (90:10), (b) CSNC1, (c) CSNC2, (d) CSNC3, (e) CSNC4, and (f) CSNC5.

(90:10) system. It is interesting to note that the crystalline nature of NCPEs (Figure 3 ) is largely reduced compared to CS : LiTf (90:10) system (Figure 1(b)). In the diffractogram of Figure 3, the crystallinity for 2 and 4 wt.\% of $\mathrm{Al}_{2} \mathrm{O}_{3}$ is largely reduced; however from 6 to $10 \mathrm{wt} . \%$ of $\mathrm{Al}_{2} \mathrm{O}_{3}$ the crystallinity is again increased. The absence of crystalline 


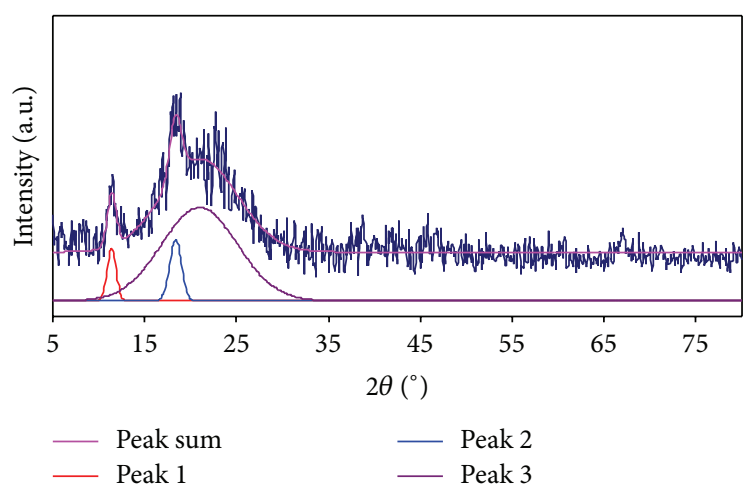

(a)

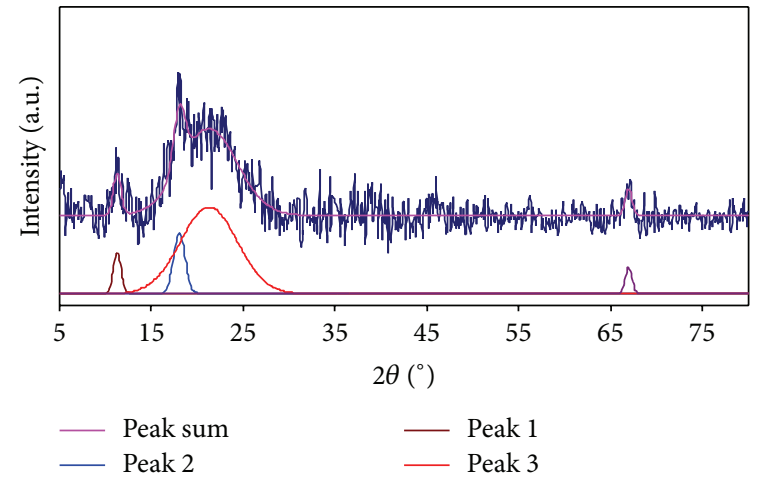

(b)

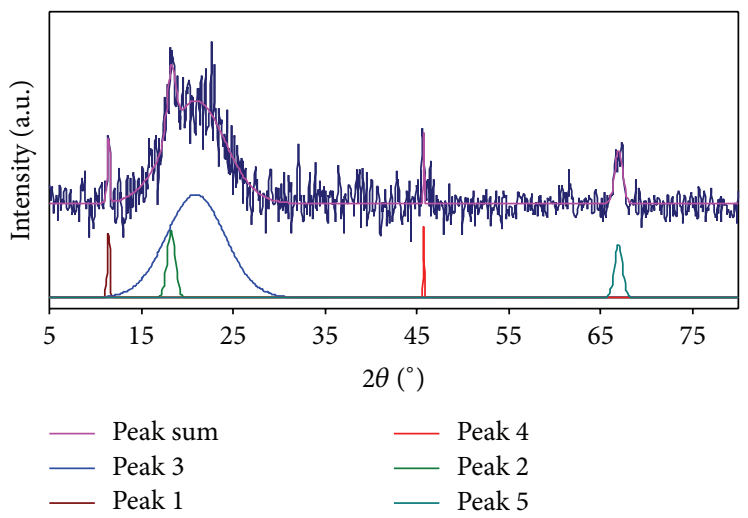

(c)

FIgURE 4: Gaussian fitting of XRD for (a) CSNC2, (b) CSNC3, and (c) CSNC5 samples.

peaks of pure $\mathrm{Al}_{2} \mathrm{O}_{3}$ nanoparticles at 2 and $4 \mathrm{wt}$.\% indicates good dispersion and mixing between the polymer electrolyte and the nano- $\mathrm{Al}_{2} \mathrm{O}_{3}$ filler. The crystalline peaks at $45.7^{\circ}$ and $67.2^{\circ}$ degree for NCPEs above 4 wt. $\%$ are due to the crystalline peaks of $\mathrm{Al}_{2} \mathrm{O}_{3}$ nanoparticles.

To further study the crystalline structure of the samples Origin 8 software has been employed to obtain the full width at half maximum (FWHM). From the FWHM the crystallite size of the nanocomposite samples can be estimated by using the Debye-Scherrer formula [22]:

$$
L=\frac{0.9 \lambda}{\Delta 2 \theta_{b} \cos \theta_{b}},
$$

where $\lambda$ is $\mathrm{X}$-ray wavelength, $\Delta 2 \theta_{b}$ is full width at half maximum (FWHM), and $\theta_{b}$ is the peak location. Figure 4 depicts the Gaussian fitting on CSNC2, CSNC3, and CSNC5 samples. The obtained FWHM from Gaussian fitting and the calculated crystallite size from the Debye-Scherrer formula are presented in Table 2. From FWHM, crystallite size $(L)$, and degree of crystallinity $(\chi)$ values (Table 2 ), it can be understood that CSNC2 is more amorphous. These results indicate the fact that high incorporation of $\mathrm{Al}_{2} \mathrm{O}_{3}$ nanoparticle concentration will increase the crystalline regions as a result of $\mathrm{Al}_{2} \mathrm{O}_{3}$ nanoparticle aggregation. The additional crystalline peaks at 45.7 and $67.2^{\circ}$ for CSNC3 and CSNC5

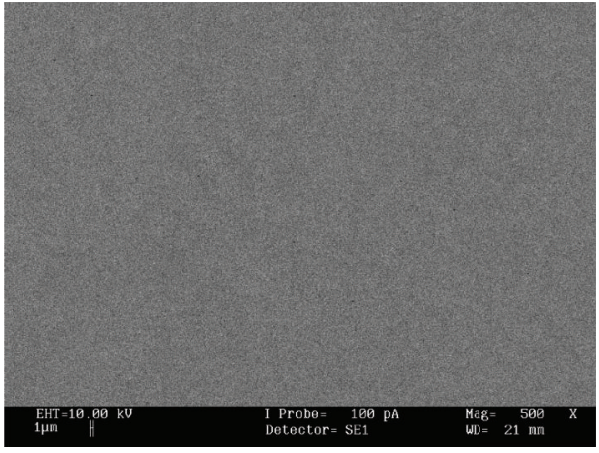

FIGURE 5: Scanning electron microscopy (SEM) image for CS : LiTf (90:10) sample.

samples can be ascribed to $\mathrm{Al}_{2} \mathrm{O}_{3}$ nanoparticle crystalline peaks. The other peaks (the peaks at $32^{\circ}, 34.4^{\circ}, 36^{\circ}$, and $39^{\circ}$ ) of $\mathrm{Al}_{2} \mathrm{O}_{3}$ nanoparticles also appeared in CSNC3 and CSNC5 samples but with smaller intensities.

3.2. Morphological Study. Figure 5 shows the surface morphology of CS : LiTf $(90: 10)$ sample. SEM is able to investigate surface structure and one of the advantages is that the range of magnification is wide allowing the investigator to 
TABLe 2: $2 \theta^{\circ}$, FWHM, crystallite size $(L)$, and degree of crystallinity $(\chi)$ for CSNC2, CSNC3, and CSNC5 NCPEs.

\begin{tabular}{lcccc}
\hline Sample designation & $2 \theta\left(^{\circ}\right)$ & FWHM $(\mathrm{rad})$ & $L\left(\mathrm{~A}^{\circ}\right)$ & Degree of crystallinity $(\%)$ \\
\hline CSNC2 & 21 & 0.143 & 10 & 8.4 \\
CSNC3 & 21.2 & 0.108 & 12 & 9.7 \\
CSNC5 & 20.9 & 0.109 & 13 & 12.3 \\
\hline
\end{tabular}

easily focus on an area of interest of the sample [23]. Before observation, the SPE and NCPE films were attached to aluminum holder using a conductive tape and then coated with a thin layer of gold. The SEM characterizations were carried out in order to understand the morphological changes during LiTf addition to chitosan. Figure 5 shows a smooth and almost homogeneous surface for CS : $\operatorname{LiTf}(90: 10)$ sample.

SEM and EDAX are carried out to detect the surface morphology of nanocomposite polymer electrolytes based on (1$x)(0.9 \mathrm{CS}: 0.1 \mathrm{LiTf})-x \mathrm{Al}_{2} \mathrm{O}_{3}(0.02 \leq x \leq 0.1)$. The combined usage of SEM-EDX is an attempt to understand the structural and compositional complexity of the samples. Fortunately, the surface morphology is almost smooth and homogeneous for 2 and 4 wt.\% of $\mathrm{Al}_{2} \mathrm{O}_{3}$ nanoparticle, as depicted in Figures 6(a) and 6(b), which strongly supports the XRD results. However, a large number of white clusters appeared on the surface of NCPEs from 6 to $10 \mathrm{wt} . \%$ of $\mathrm{Al}_{2} \mathrm{O}_{3}$ nanoparticle (Figures 6(c)-6(e)) indicating that $\mathrm{Al}_{2} \mathrm{O}_{3}$ nanoparticles at higher concentrations are not well distributed. Thus the morphology of NCPEs became rough when the concentration of $\mathrm{Al}_{2} \mathrm{O}_{3}$ nanoparticles increased beyond $4 \mathrm{wt} . \%$ and these results are in good agreement with the XRD results. The sharp peak of $\mathrm{Al}$ with a high intensity observed in EDAX results as presented in Figure 6(f) confirms that these white clusters are aggregates of $\mathrm{Al}_{2} \mathrm{O}_{3}$ nanoparticles. This again supports the XRD results.

3.3. DC Conductivity and Dielectric Constant Analysis. Figure 7 shows the variation of DC conductivity for CS: LiTf system with various concentrations of alumina nanoparticle. It is obvious that at low filler concentrations (2 to 4 wt.\%) the DC conductivity increased. The increase of DC conductivity by four orders can be more understood from the dielectric constant study. However, at high filler concentrations (6 to 10 wt.\%) the conductivity decreased. The high value of DC conductivity for $(1-x)(0.9 \mathrm{CS}: 0.1 \mathrm{LiTf})-x \mathrm{Al}_{2} \mathrm{O}_{3}(0.02 \leq$ $x \leq 0.1)$ nanocomposites with respect to $\mathrm{CS}: \operatorname{LiTf}(90: 10)$ solid polymer electrolyte again can be attributable to the effect of alumina nanoparticles. According to Stephan et al. [24], the Lewis acid groups of the added inorganic filler may compete with the Lewis acid-lithium cations for the formation of complexes with the polar groups $\left(\mathrm{NH}_{2}\right.$ and $\left.\mathrm{OH}\right)$ of chitosan chains as well as the anions of the added lithium salt. The occurrence of reaction between the Lewis acid-base interaction centers of the added filler and the electrolytic species results in lowering the ionic coupling and thus promotes the salt dissociation via a sort of "ion-filler complex" formation. The increase and decrease of DC conductivity can be interpreted in terms of space charge and blocking effect. It was reported that the addition of ceramic filler to the polymer matrix may create a space charge layer at the filler-polymer interface and thus assists in ion transport [25]. At higher filler concentrations the blocking effect will occur. Consequently, the more abundant alumina grains could make the long polymer chains more "immobilized" leading to a decrease conductivity [26]. This can be more understood from the TEM images for 4 wt. $\%$ and 10 wt. $\%$ of $\mathrm{Al}_{2} \mathrm{O}_{3}$ nanoparticles as depicted in Figures 8 and 9, respectively. Transmission electron microscopy (TEM) is considered the best available imaging technique for analysis of the internal structure and views of the defect structure through direct visualization especially for thin films [27]. At lower filler concentration, the interaction of the filler with the polymer as a result of hydrogen bonding would alter inductive interchain interactions lowering the crystallinity of the macromolecule, enhancing the chain movement as a result of creating a space charge layer at the filler-polymer interface as depicted in Figure 8, and thus increasing the conductivity of the system [28]. However at higher concentration the fillers aggregate as shown in Figure 9, thus leaving the polymer chains to intermolecular and intramolecular hydrogen bonding, and consequently the increase in crystalline portion is expected. This explanation can be more understood from the XRD results. Figure 4(c) clearly showed that at 10 wt. $\%$ of of $\mathrm{Al}_{2} \mathrm{O}_{3}$ nanoparticles the crystalline peaks of chitosan are enhanced as a result of nanoparticle aggregations.

Figure 10 shows the frequency dependence of dielectric constant for different alumina concentrations. The high value of dielectric constant at low frequency can be ascribed to electrode polarization effect. These high dielectric constants at low frequencies are responsible for the suppression of high frequency dielectric constant for all the compositions to a single bundle. Thus the high frequency region must be plotted separately in another figure.

Figure 11 shows that the high frequency dielectric constant is also greatly influenced by the filler concentration. The high frequency dielectric constant is important because it represents the intrinsic property of the material and is directly related to DC conductivity. It can be seen that the dielectric constant is about 19 and is four times the dielectric constant of CS : LiTf $(90: 10)$ system which is about 4.8 as shown in Figure 12. Thus the increase of DC conductivity is associated with an increase of dielectric constant.

Figure 13 depicts the concentration dependence of bulk dielectric constant and DC conductivity. It is interesting to note that the behavior of bulk dielectric constant and DC conductivity (Figure 13) with filler concentration is almost the same. Similar trends of these two important parameters with filler concentration certify the existence of a strong relationship between DC conductivity and dielectric constant. Study of these two parameters at different temperature may give further information. 


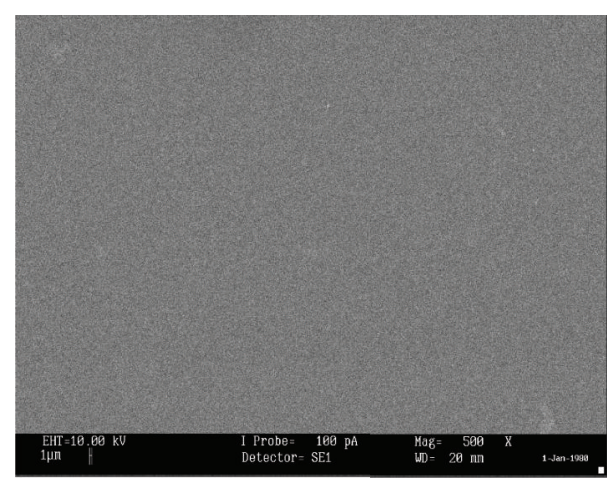

(a)

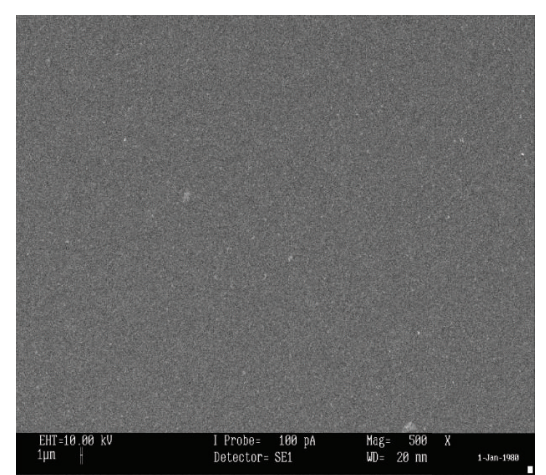

(b)

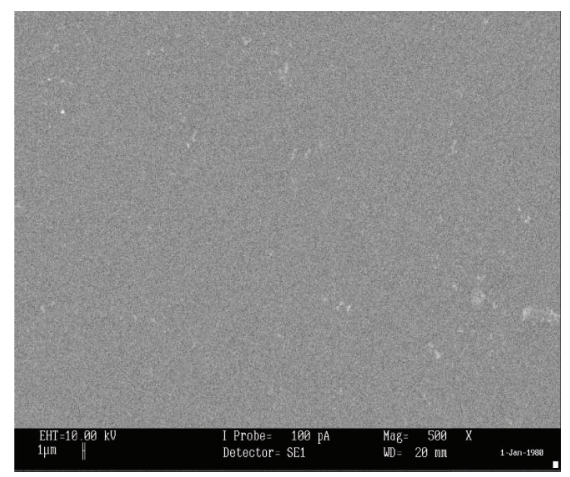

(c)

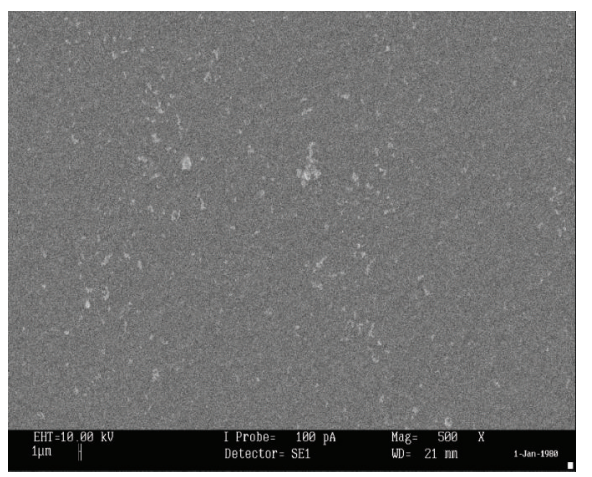

(d)

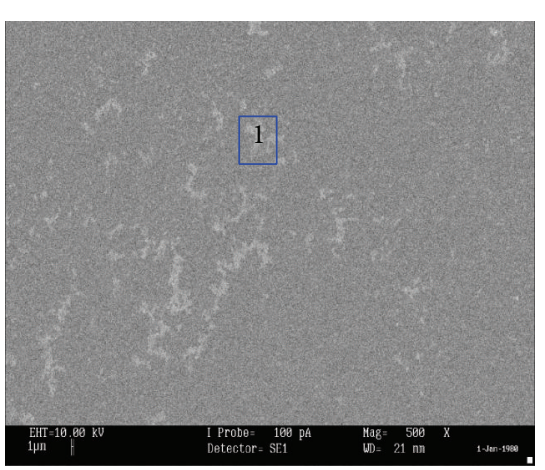

(e)

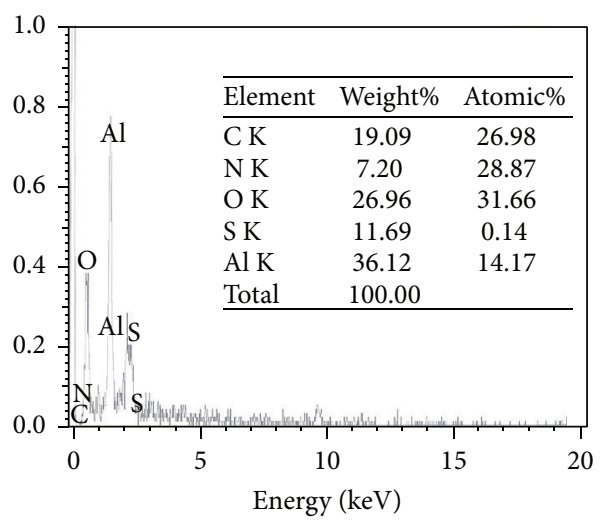

(f)

Figure 6: Scanning electron microscopy (SEM) image for (a) CSNC1, (b) CSNC2, (c) CSNC3, (d) CSNC4, (e) CSNC5, and (f) EDX for spot in box 1 .

Figure 14 shows the smooth curve between DC conductivity and bulk dielectric constant at selected temperatures. It is obvious from the plot that the bulk DC conductivity is smoothly increased with increasing bulk dielectric constant at different temperatures. The concentration dependence of bulk DC conductivity and bulk dielectric constant together with the smooth curve between DC conductivity and dielectric constants confirms the dependence of DC conductivity on dielectric constant in NCPEs based on chitosan. The increase in dielectric constant means an increase in carrier density and hence an increase in DC conductivity. Extra research work is required in this field to confirm the dependence of DC conductivity on dielectric constant, thus reformulating the Arrhenius equation. Recently, Petrowsky and Frech $[29,30]$ hypothesized that the DC conductivity is not only a function of temperature but also dependent on the dielectric constant for low salt concentration in organic liquid electrolytes. They have also interpreted the non-Arrhenius behavior of DC conductivity as a result of dependence of preexponential factor, $\sigma_{o}$, on the dielectric constant, $\sigma_{\left(\varepsilon^{\prime}, T\right)}=$ $\sigma_{o\left(\varepsilon^{\prime}(T)\right)} \exp ^{\left(-E_{a} / K_{B} T\right)}$. The difference of this hypothesis for solid electrolyte is that the preexponential factor, $\sigma_{o}$, is constant. From the results of this work it is understood that ion transport is not an easy task and can be considered 


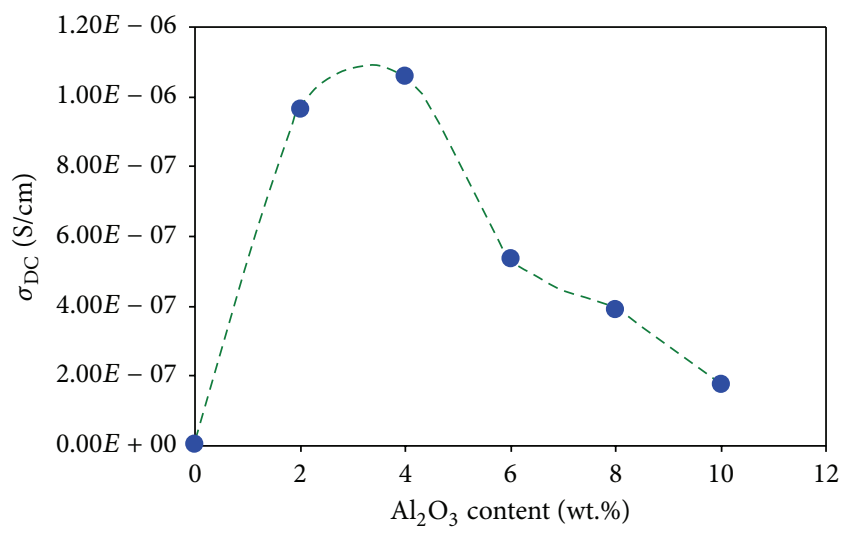

FIgURE 7: The ionic conductivity of chitosan: LiTf (CSC6) with various concentrations of $\mathrm{Al}_{2} \mathrm{O}_{3}$.

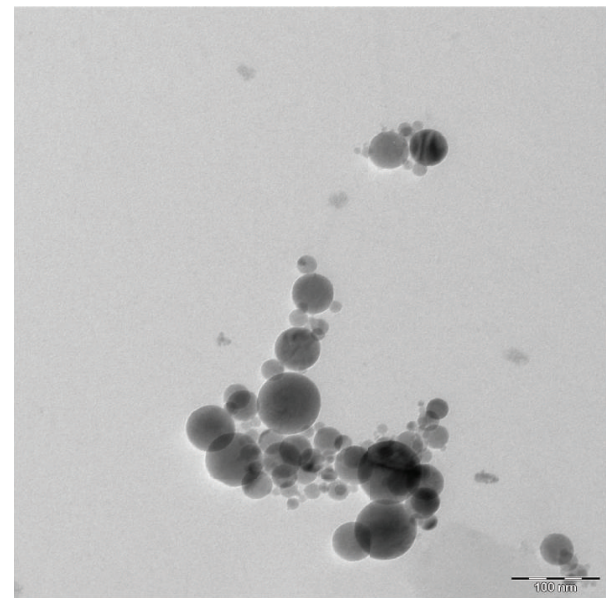

Figure 8: TEM image for CSNC2 (4 wt.\% of $\mathrm{Al}_{2} \mathrm{O}_{3}$ ).

as a complicated subject in solid polymer electrolytes as a branch of condensed matter physics. The temperaturedependent ionic conductivity for a solid or nanocomposite polymer electrolyte below the glass transition temperature is usually interpreted in terms of Arrhenius equation without any insight into the fundamental mechanisms governing ion transport. In our previous work [10, 19], we concluded the fact that the Arrhenius equation should be reformulated to another form which must contain both the temperature and dielectric constant is required. The distinguishable behavior between DC conductivity and dielectric constant at different temperatures as exhibited in Figure 14 motivates me to take a novel approach to explain a DC ionic conductivity. Thus my hypothesis is that in addition to temperature the dielectric constant must exist in Arrhenius equation as follows:

$$
\sigma\left(T, \varepsilon^{\prime}\right)=\sigma_{o} \exp ^{\left(-E_{a} / K_{B} T \varepsilon^{\prime}\right)}
$$

This new empirical equation which is a modified or reformulated Arrhenius equation must be considered to calculate the activation energy. From the fundamental point of

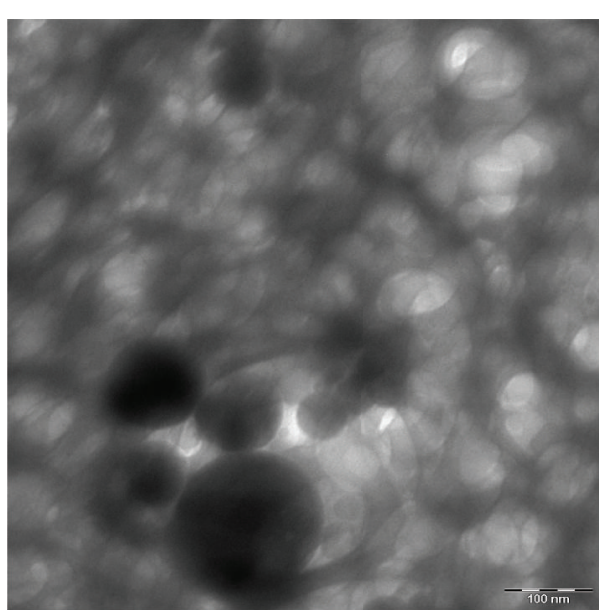

Figure 9: TEM image for CSNC5 (10 wt.\% of $\mathrm{Al}_{2} \mathrm{O}_{3}$ ).

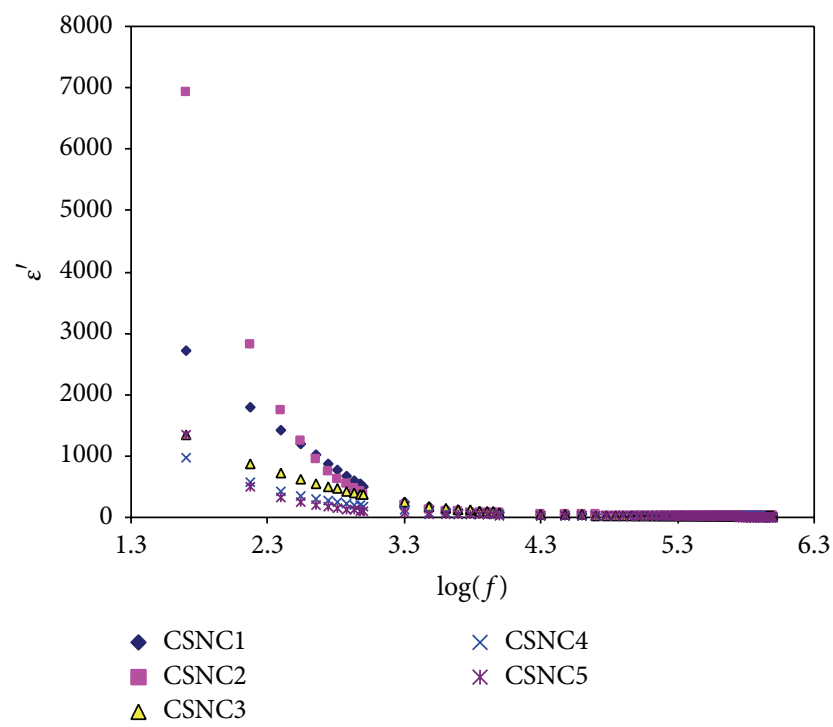

FIGURE 10: Composition dependence of dielectric constant for (1$x)(0.9 \mathrm{CS}: 0.1 \mathrm{LiTf})-x \mathrm{Al}_{2} \mathrm{O}_{3}(0.02 \leq x \leq 0.1)$ NCPEs at room temperature.

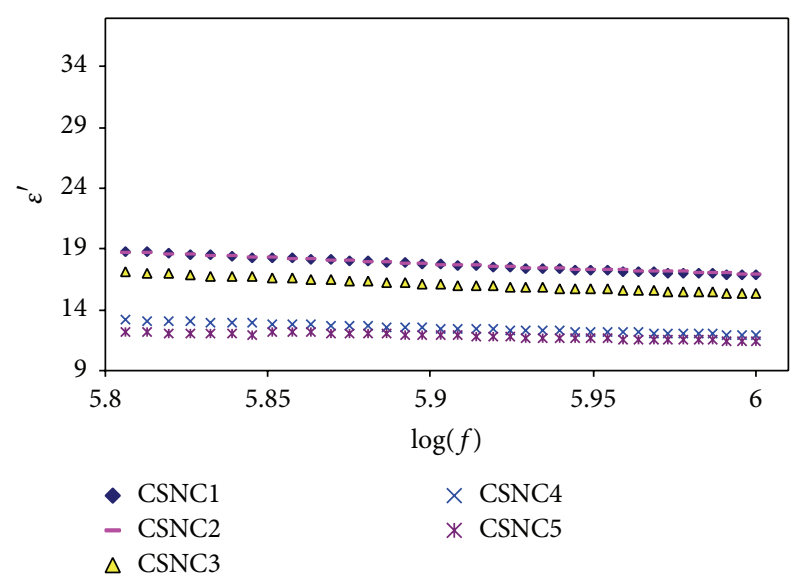

FIGURE 11: Composition dependence of bulk dielectric constant for CS : $\operatorname{LiTf}(90: 10)-x \mathrm{Al}_{2} \mathrm{O}_{3}(2 \leq x \leq 0.1)$ NCPEs. 


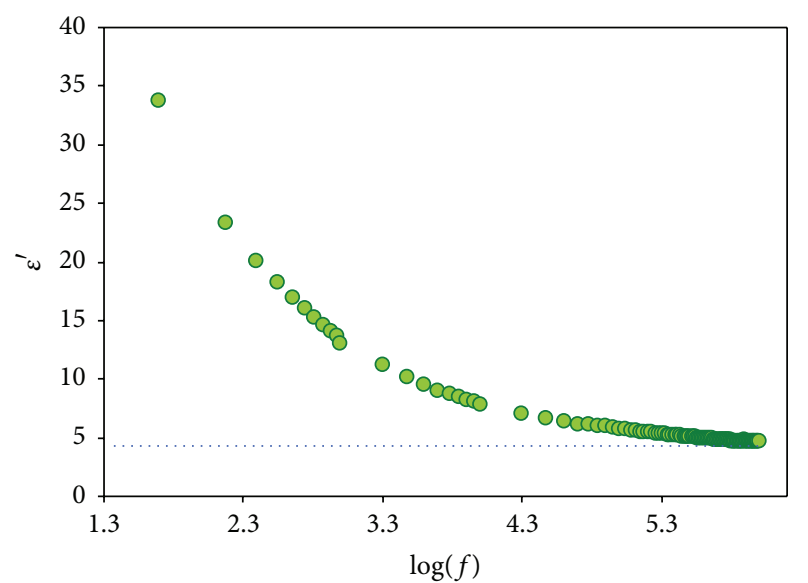

Figure 12: Dielectric constant as a function of frequency for CS : LiTf system at room temperature.

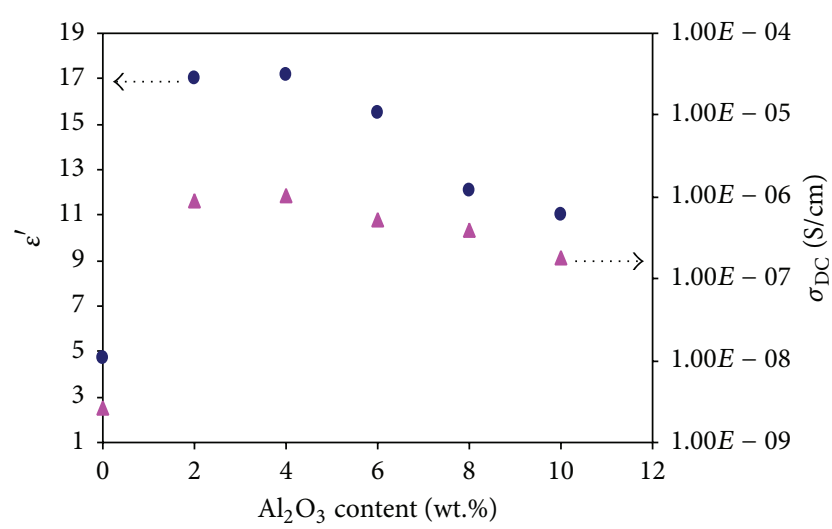

Figure 13: Dependence of bulk dielectric constant $\left(\varepsilon^{\prime}\right.$ at $\left.1 \mathrm{MHz}\right)$ and DC conductivity of chitosan : $\operatorname{LiTf}(90: 10)$ on $\mathrm{Al}_{2} \mathrm{O}_{3}$ concentration.

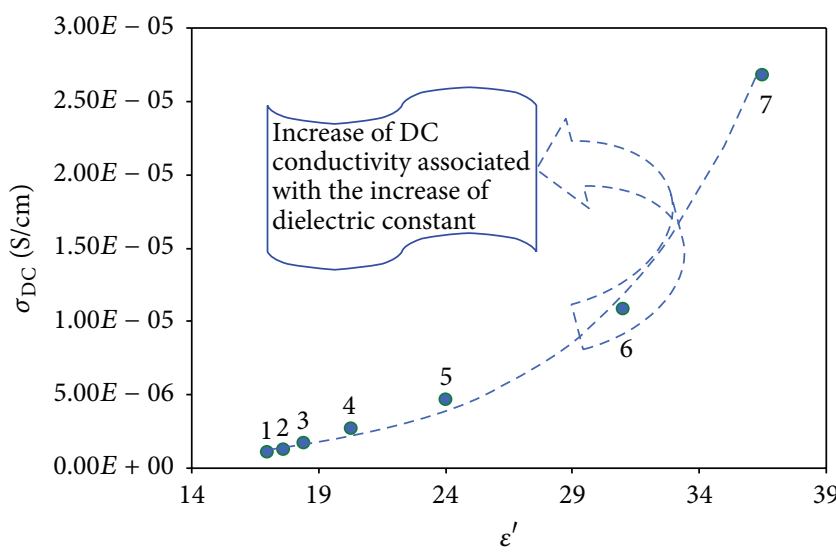

FIGURE 14: DC conductivity dependence on dielectric constant $\left(\varepsilon^{\prime}\right.$ at $1 \mathrm{MHz}$ ) at (1) $303,(2) 308$, (3) 313, (4) $318,(5) 323,(6) 328$, and (7) $333 \mathrm{~K}$ for CSNC2 system.

view, dielectric relaxation and ion conduction mechanism in solids are the most intensively researched topics in condensed matter physics and especially ionic transport in polymer

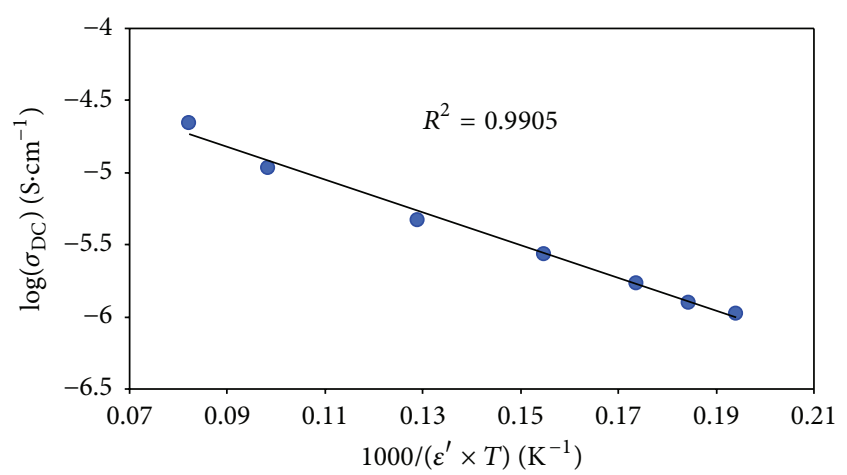

FIgure 15: Temperature dependence of DC conductivity (reformulated Arrhenius equation) for CSNC2 system.

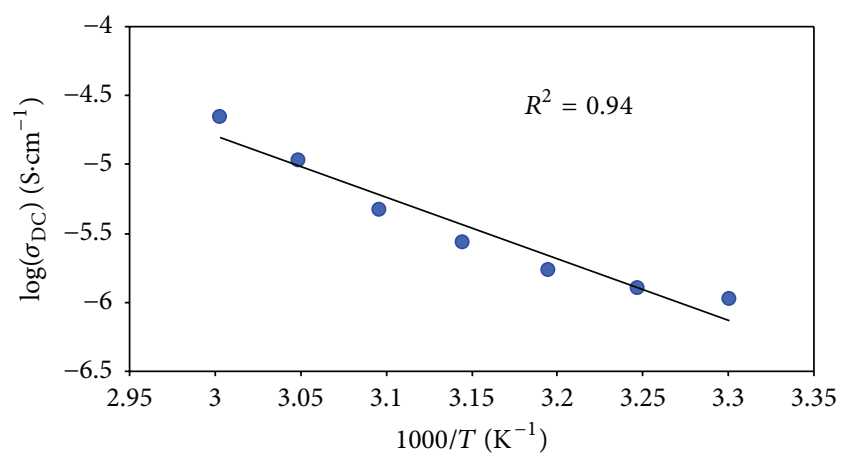

FIGURE 16: Temperature dependence of DC conductivity (Arrhenius equation) for CSNC2 system.

electrolytes. Ion transport is complex and depends on factors such as salt concentration and dielectric constant of host polymer [10]. The increase of dielectric constant at higher temperatures can be ascribed to the fact that the movement of polymer chain segments and side groups becomes easier at elevated temperatures and thus the dissociation of ion pairs would increase and result in increase in DC ionic conductivity [19]. Figure 15 shows the DC conductivity versus $1000 /\left(\varepsilon^{\prime} \times T\right)$. The linear behavior of DC conductivity (Figure 15) with a regression value of 0.99 reveals the necessary existence of dielectric constant in Arrhenius equation. The DC conductivity versus $1000 / T$ as exhibited in Figure 16 is less linear and the regression value is 0.94 . The difference between Arrhenius and reformulated Arrhenius equation is distinguishable from Figures 15 and 16. The more linear behavior of Figure 15 reveals the validity of reformulated Arrhenius equation. The main conclusion in this work is that the dielectric constant can play a major role in ion transport and thus studies must be directed to develop or synthesize a high dielectric constant polymer in order to achieve a high DC conductivity at room temperature.

3.4. Relaxation Processes: Electric Modulus Study. Figure 17 depicts the frequency dependence of real part of electric 


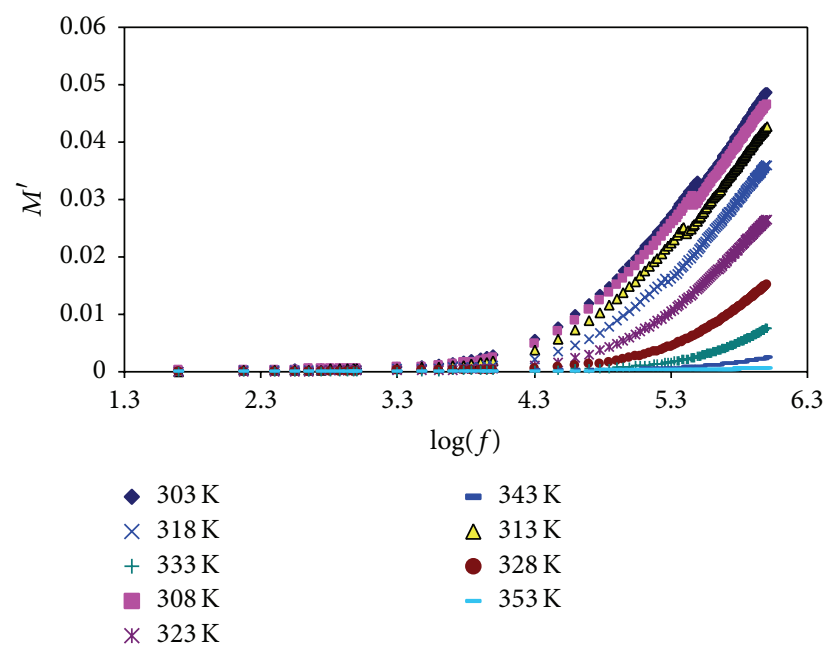

FigURE 17: Frequency dependence of $M^{\prime}$ at different temperature for CSNC2 sample.

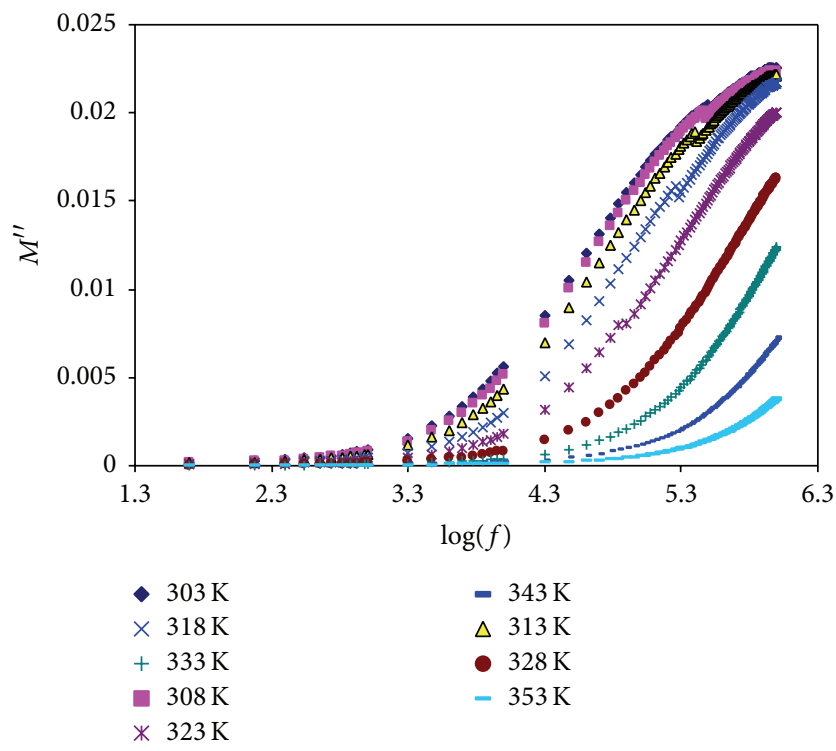

Figure 18: Frequency dependence of $M^{\prime \prime}$ at different temperature for CSNC2 sample.

modulus at different temperatures. The observed long tail at low frequencies is attributable to the large value of electrode polarization capacitance. The decrease in $M^{\prime}$ value at high temperature is due to the decrease of resistance of the sample and increase in electrode polarization.

Figure 18 shows the variation of imaginary part of electric modulus with frequency at selected temperatures. At low temperatures peaks were observed. The peaks are asymmetric and broad which indicate the distribution of relaxation times. However at high temperatures the peaks disappeared possibly due to the frequency limitation.

The Argand plots at different temperatures for the NCPE (CSNC2) are shown in Figures 19(a)-19(c). It can be seen that the Argand plots exhibit incomplete semicircular arc. This indicates the non-Debye type relaxation process. The Debye model is developed to noninteracting identical dipoles [31]. Thus the non-Debye behavior is due to the fact that in real material there are more than one type of polarization mechanism and a lot of interactions between ions and dipoles. These result in a distribution of relaxation time. Moreover it can be seen that with increasing temperature $M^{\prime \prime}-M^{\prime}$ curve deviates more from the semicircular arc. This can be ascribed to the increase in conductivity. With increase in temperature $Z_{i}$ and $Z_{r}$ values decrease and thus $M^{\prime \prime}$ and $M^{\prime}$ values $\left(M^{\prime \prime}=\right.$ $\omega C_{o} Z_{r}, M^{\prime}=\omega C_{o} Z_{i}$ ) deviate more towards the origin.

\section{Conclusions}

In this research work solid and nanocomposite polymer electrolytes based on chitosan have been prepared by the well-known solution cast technique. The broadening of XRD peaks for CS : LiTf system reveals the disruption of crystalline nature of chitosan (CS). The deconvolution of the diffractogram of nanocomposite solid polymer electrolytes confirms the increase of amorphous domain for the samples which contains $\mathrm{Al}_{2} \mathrm{O}_{3}$ nanoparticle up to $4 \mathrm{wt} . \%$. Further incorporation of alumina nanoparticles (6 to $10 \mathrm{wt} . \% \mathrm{Al}_{2} \mathrm{O}_{3}$ ) results in crystallinity increase (large crystallite size). The SEM analysis reveals smooth surface for the samples containing lower concentration of alumina ( 2 to $4 \mathrm{wt} . \%$ of $\mathrm{Al}_{2} \mathrm{O}_{3}$ ). The morphological (SEM and EDX) analysis well supported the XRD results. Similar trends of DC conductivity with $\mathrm{Al}_{2} \mathrm{O}_{3}$ concentration are related to the behavior of dielectric constant with alumina content. Form the TEM results the phenomena of space charge and blocking effects were well understood. The smooth exponential curve between DC conductivity and dielectric constant at different temperatures indicates the necessary reformulation of Arrhenius equation. The modified or reformulated Arrhenius equation $\left(\sigma_{\left(\varepsilon^{\prime}, T\right)}=\sigma_{o} \exp ^{\left(-E_{a} / K_{B} \varepsilon^{\prime} T\right)}\right)$ is achieved from the plot of DC conductivity versus dielectric constant. The more linear behavior of DC conductivity versus $1000 /\left(\varepsilon^{\prime} \times T\right)$ reveals the validity of reformulated Arrhenius equation. The incomplete semicircle of Argand plots indicates that the relaxation processes are of non-Debye type.

\section{Competing Interests}

The author declares that there are no competing interests regarding the publication of this paper.

\section{Acknowledgments}

The author gratefully acknowledges the financial support from University of Malaya in the form of grant (grant no. PS214/2009A) for this research project. The author also wishes to thank the Ministry of Higher Education and Scientific Research/Kurdistan Regional Government for the scholarship awarded. 


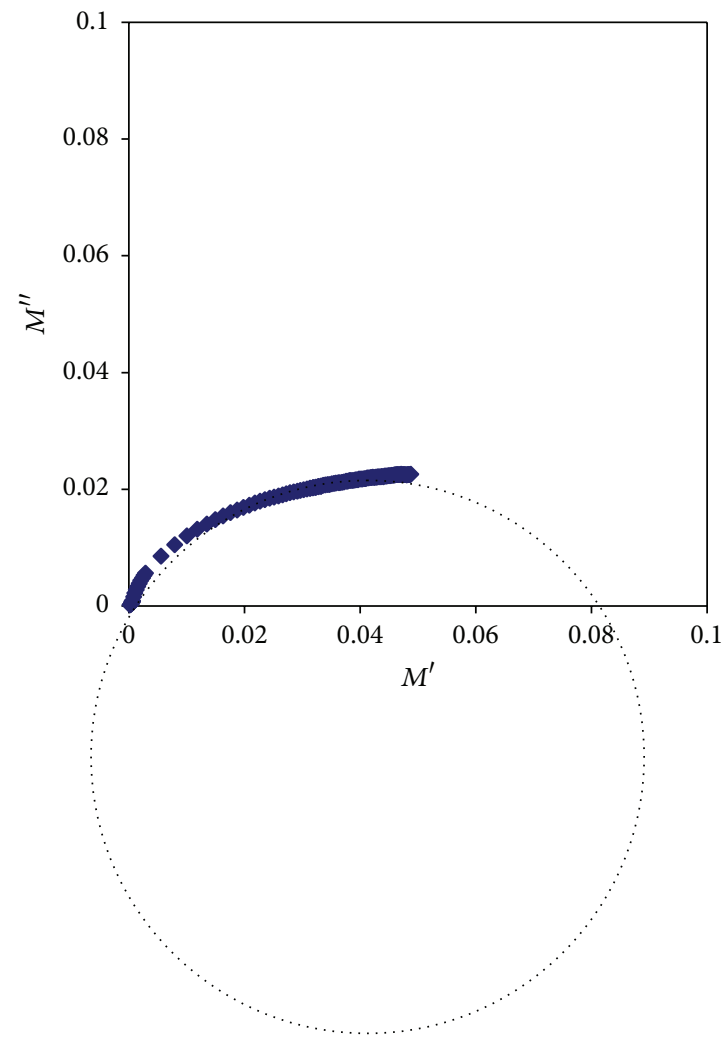

(a)

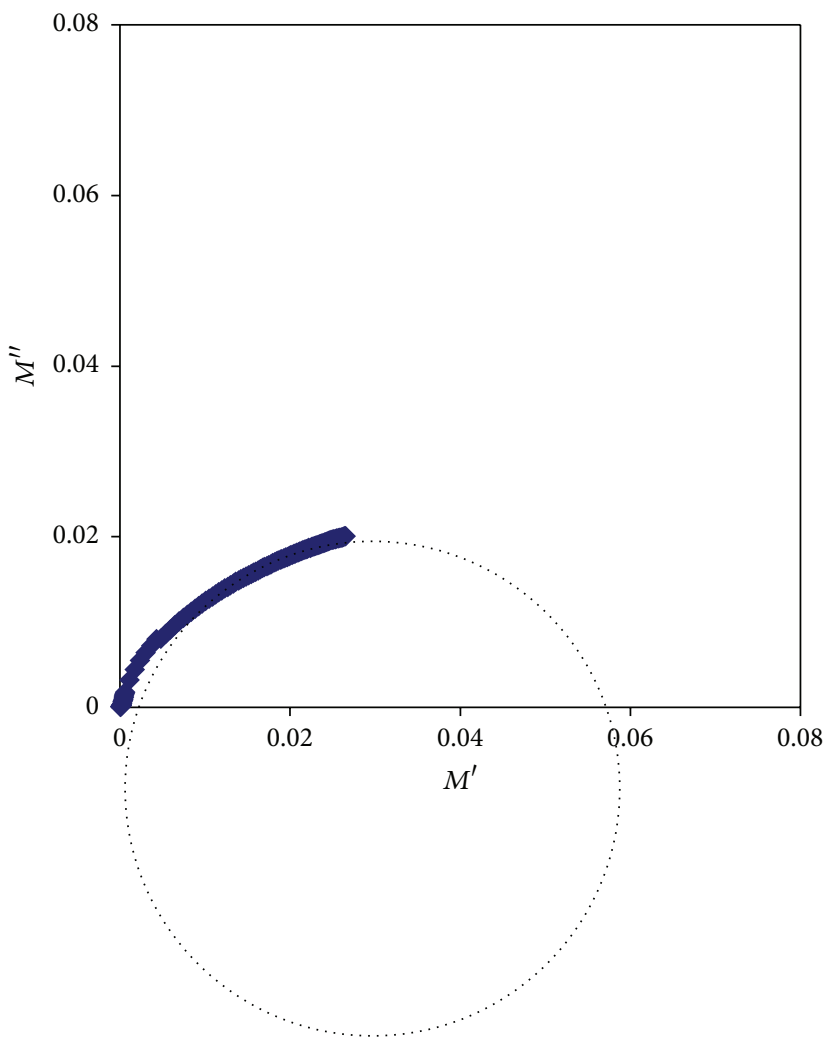

(b)

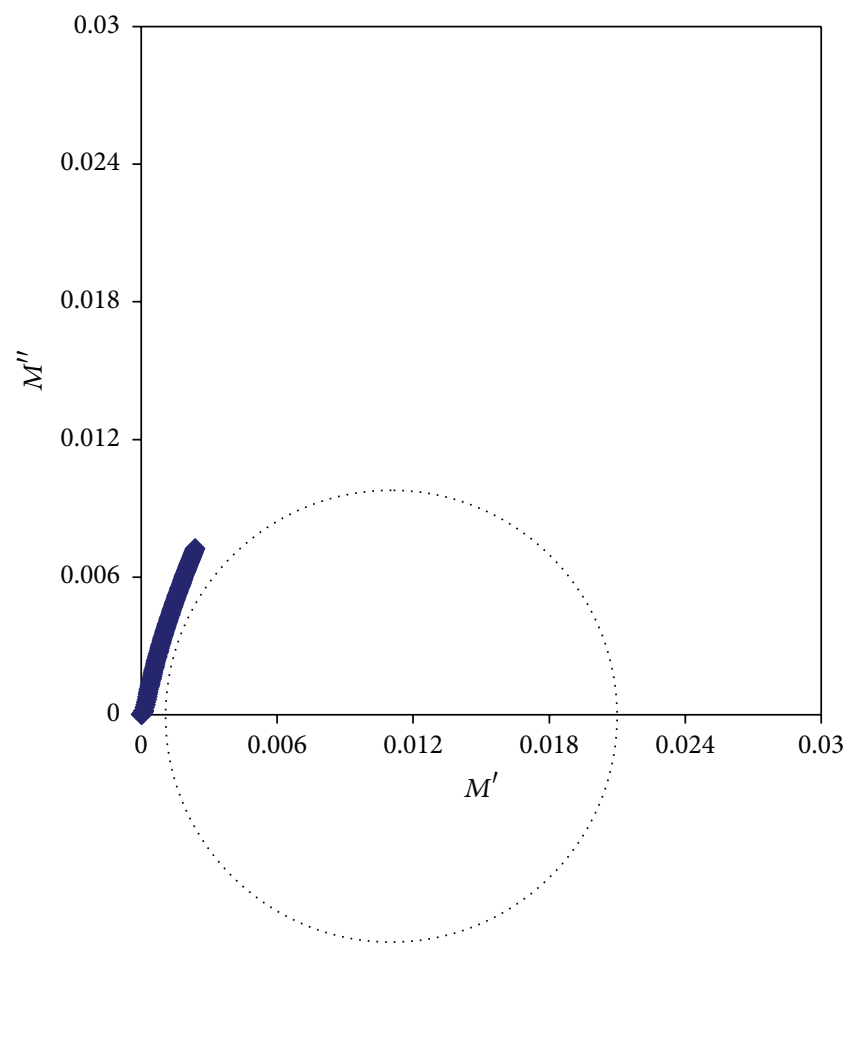

(c)

Figure 19: Argand plots for NCPE (CSNC2) at (a) $303 \mathrm{~K}$, (b) $323 \mathrm{~K}$, and (c) $343 \mathrm{~K}$. 


\section{References}

[1] M. Rinaudo, "Chitin and chitosan: properties and applications," Progress in Polymer Science, vol. 31, no. 7, pp. 603-632, 2006.

[2] C. G. A. Lima, R. S. de Oliveira, S. D. Figueiró, C. F. Wehmann, J. C. Góes, and A. S. B. Sombra, "DC conductivity and dielectric permittivity of collagen-chitosan films," Materials Chemistry and Physics, vol. 99, no. 2-3, pp. 284-288, 2006.

[3] P. Agrawal, G. J. Strijkers, and K. Nicolay, "Chitosan-based systems for molecular imaging," Advanced Drug Delivery Reviews, vol. 62, no. 1, pp. 42-58, 2010.

[4] M. Cheng, J. Deng, F. Yang, Y. Gong, N. Zhao, and X. Zhang, "Study on physical properties and nerve cell affinity of composite films from chitosan and gelatin solutions," Biomaterials, vol. 24, no. 17, pp. 2871-2880, 2003.

[5] H. Nagahama, H. Maeda, T. Kashiki, R. Jayakumar, T. Furuike, and H. Tamura, "Preparation and characterization of novel chitosan/gelatin membranes using chitosan hydrogel," Carbohydrate Polymers, vol. 76, no. 2, pp. 255-260, 2009.

[6] Y. Wan, K. A. M. Creber, B. Peppley, and V. T. Bui, "Chitosanbased solid electrolyte composite membranes: I. Preparation and characterization," Journal of Membrane Science, vol. 280, no. 1-2, pp. 666-674, 2006.

[7] C. K. S. Pillai, W. Paul, and C. P. Sharma, "Chitin and chitosan polymers: chemistry, solubility and fiber formation," Progress in Polymer Science, vol. 34, no. 7, pp. 641-678, 2009.

[8] N. M. El-Sawy, H. A. Abd El-Rehim, A. M. Elbarbary, and E.S. A. Hegazy, "Radiation-induced degradation of chitosan for possible use as a growth promoter in agricultural purposes," Carbohydrate Polymers, vol. 79, no. 3, pp. 555-562, 2010.

[9] Y. Wan, K. A. M. Creber, B. Peppley, and V. T. Bui, "Ionic conductivity of chitosan membranes," Polymer, vol. 44, no. 4, pp. 1057-1065, 2003.

[10] S. B. Aziz and Z. H. Z. Abidin, "Electrical conduction mechanism in solid polymer electrolytes: new concepts to arrhenius equation," Journal of Soft Matter, vol. 2013, Article ID 323868, 8 pages, 2013.

[11] M. M. Costa, A. J. Terezo, A. L. Matos, W. A. Moura, J. A. Giacometti, and A. S. B. Sombra, "Impedance spectroscopy study of dehydrated chitosan and chitosan containing $\mathrm{LiClO}_{4}$," Physica B: Condensed Matter, vol. 405, no. 21, pp. 4439-4444, 2010.

[12] S. R. Mohapatra, A. K. Thakur, and R. N. P. Choudhary, "Effect of nanoscopic confinement on improvement in ion conduction and stability properties of an intercalated polymer nanocomposite electrolyte for energy storage applications," Journal of Power Sources, vol. 191, no. 2, pp. 601-613, 2009.

[13] S. Mulmi, C. H. Park, H. K. Kim, C. H. Lee, H. B. Park, and Y. M. Lee, "Surfactant-assisted polymer electrolyte nanocomposite membranes for fuel cells," Journal of Membrane Science, vol. 344, no. 1-2, pp. 288-296, 2009.

[14] G. A. Kontos, A. L. Soulintzis, P. K. Karahaliou et al., "Electrical relaxation dynamics in $\mathrm{TiO}_{2}$ - polymer matrix composites," eXPRESS Polymer Letters, vol. 1, no. 12, pp. 781-789, 2007.

[15] P. Thomas, S. Satapathy, K. Dwarakanath, and K. B. R. Varma, "Dielectric properties of poly (vinylidene fluoride)/ $\mathrm{CaCu}_{3} \mathrm{Ti}_{4} \mathrm{O}_{12}$ nanocrystal composite thick films," eXPRESS Polymer Letters, vol. 4, no. 10, pp. 632-643, 2010.

[16] E. López-Chávez, J. M. Martínez-Magadán, R. Oviedo-Roa, J. Guzmán, J. Ramírez-Salgado, and J. Marín-Cruz, "Molecular modeling and simulation of ion-conductivity in chitosan membranes," Polymer, vol. 46, no. 18, pp. 7519-7527, 2005.
[17] S. B. Aziz, " $\mathrm{Li}^{+}$ion conduction mechanism in poly $(\varepsilon-$ caprolactone)-based polymer electrolyte," Iranian Polymer Journal, vol. 22, no. 12, pp. 877-883, 2013.

[18] S. B. Aziz, "Study of electrical percolation phenomenon from the dielectric and electric modulus analysis," Bulletin of Materials Science, vol. 38, no. 6, pp. 1597-1602, 2015.

[19] S. B. Aziz and Z. H. Z. Abidin, "Ion-transport study in nanocomposite solid polymer electrolytes based on chitosan: electrical and dielectric analysis," Journal of Applied Polymer Science, vol. 132, Article ID 41774, 2015.

[20] S. B. Aziz and Z. H. Z. Abidin, "Role of hard-acid/hardbase interaction on structural and dielectric behavior of solid polymer electrolytes based on chitosan- $\mathrm{XCF}_{3} \mathrm{SO}_{3}\left(\mathrm{X}=\mathrm{Li}^{+}, \mathrm{Na}^{+}\right.$, $\mathrm{Ag}^{+}$)," Journal of Polymers, vol. 2014, Article ID 906780, 9 pages, 2014.

[21] S. Ahmad and S. A. Agnihotry, "Effect of nano $\gamma-\mathrm{Al}_{2} \mathrm{O}_{3}$ addition on ion dynamics in polymer electrolytes," Current Applied Physics, vol. 9, no. 1, pp. 108-114, 2009.

[22] S. B. Aziz, Z. H. Z. Abidin, and M. F. Z. Kadir, "Innovative method to avoid the reduction of silver ions to silver nanoparticles $\left(\mathrm{Ag}^{+} \rightarrow \mathrm{Ag}^{\circ}\right)$ in silver ion conducting based polymer electrolytes," Physica Scripta, vol. 90, no. 3, Article ID 035808, 2015.

[23] C. T. K.-H. Stadtländer, "Scanning electron microscopy and transmission electron microscopy of mollicutes: challenges and opportunities," in Modern Research and Educational Topics in Microscopy, pp. 122-131, Formatex, 2007.

[24] A. M. Stephan, K. S. Nahm, M. A. Kulandainathan, G. Ravi, and J. Wilson, "Poly(vinylidene fluoride-hexafluoropropylene) (PVdF-HFP) based composite electrolytes for lithium batteries," European Polymer Journal, vol. 42, no. 8, pp. 1728-1734, 2006.

[25] R. Kumar, A. Subramania, N. T. K. Sundaram, G. V. Kumar, and I. Baskaran, "Effect of $\mathrm{MgO}$ nanoparticles on ionic conductivity and electrochemical properties of nanocomposite polymer electrolyte," Journal of Membrane Science, vol. 300, no. 1-2, pp. 104-110, 2007.

[26] M. A. K. L. Dissanayake, P. A. R. D. Jayathilaka, R. S. P. Bokalawala, I. Albinsson, and B.-E. Mellander, "Effect of concentration and grain size of alumina filler on the ionic conductivity enhancement of the (PEO) ${ }_{9} \mathrm{LiCF}_{3} \mathrm{SO}_{3}: \mathrm{Al}_{2} \mathrm{O}_{3}$ composite polymer electrolyte," Journal of Power Sources, vol. 119-121, pp. 409-414, 2003.

[27] S. Sinha Ray and M. Okamoto, "Polymer/layered silicate nanocomposites: a review from preparation to processing," Progress in Polymer Science, vol. 28, no. 11, pp. 1539-1641, 2003.

[28] M. Moreno, M. A. S. Ana, G. Gonzalez, and E. Benavente, "Poly(acrylonitrile)-montmorillonite nanocomposites. Effects of the intercalation of the filler on the conductivity of composite polymer electrolytes," Electrochimica Acta, vol. 55, no. 4, pp. 1323-1327, 2010.

[29] M. Petrowsky and R. Frech, "Temperature dependence of ion transport: the compensated arrhenius equation," The Journal of Physical Chemistry B, vol. 113, no. 17, pp. 5996-6000, 2009.

[30] M. Petrowsky and R. Frech, "Salt concentration dependence of the compensated Arrhenius equation for alcohol-based electrolytes," Electrochimica Acta, vol. 55, no. 4, pp. 1285-1288, 2010.

[31] R. M. Hill and L. A. Dissado, "Debye and non-Debye relaxation," Journal of Physics C: Solid State Physics, vol. 18, no. 19, pp. 38293836, 1985. 

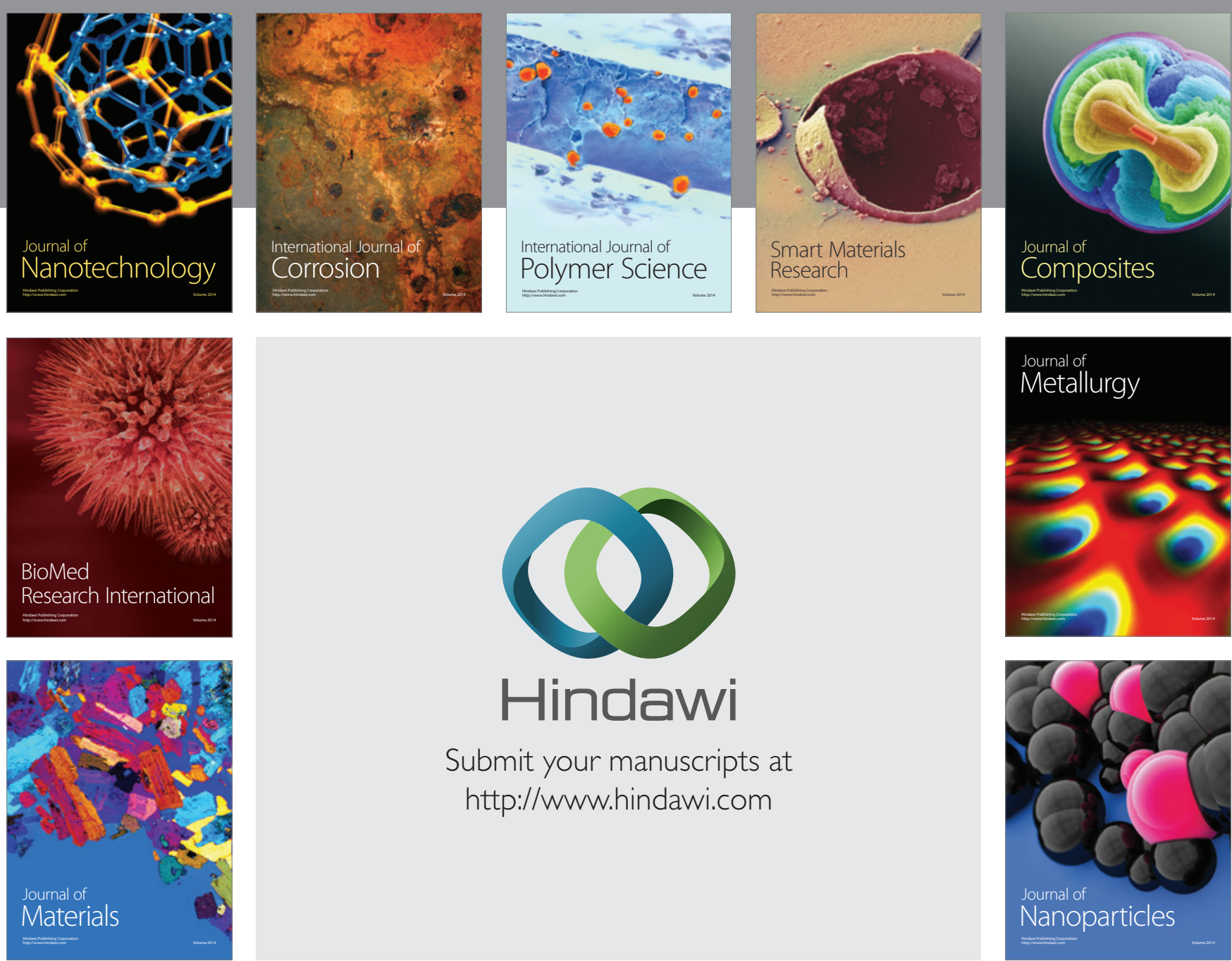

\section{Hindawi}

Submit your manuscripts at

http://www.hindawi.com

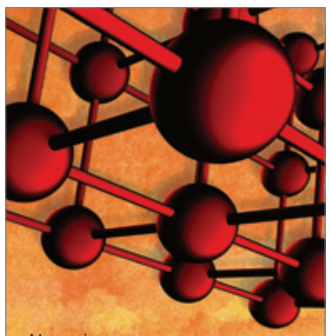

Materials Science and Engineering
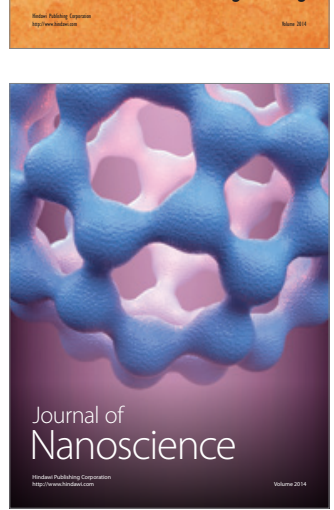
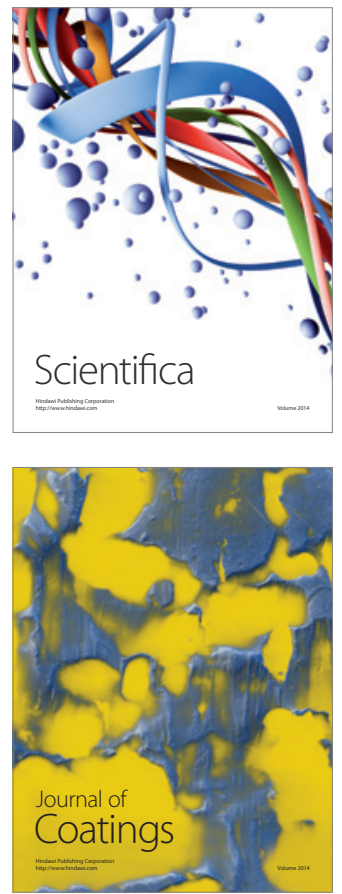
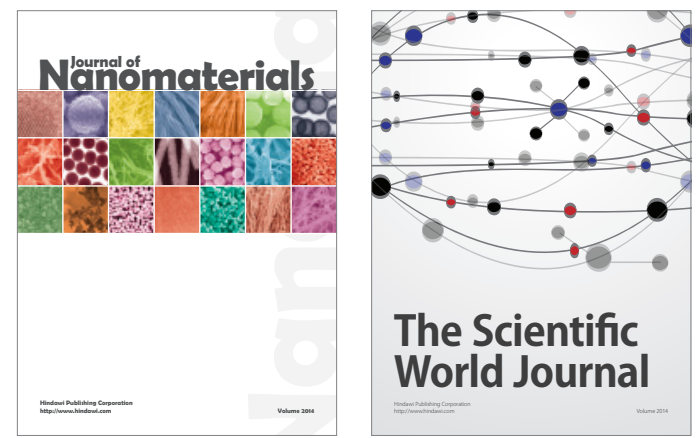

The Scientific World Journal
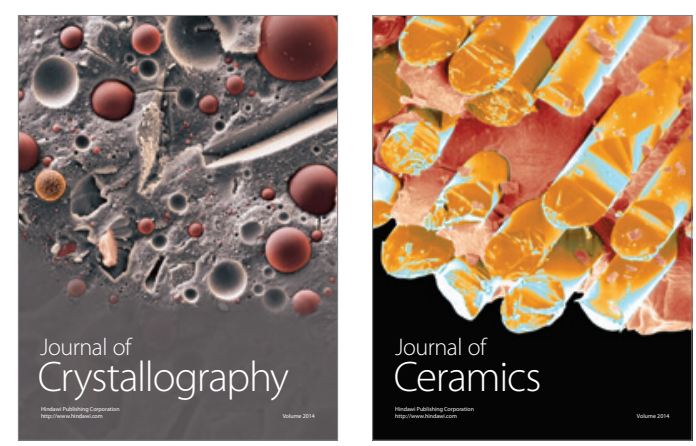
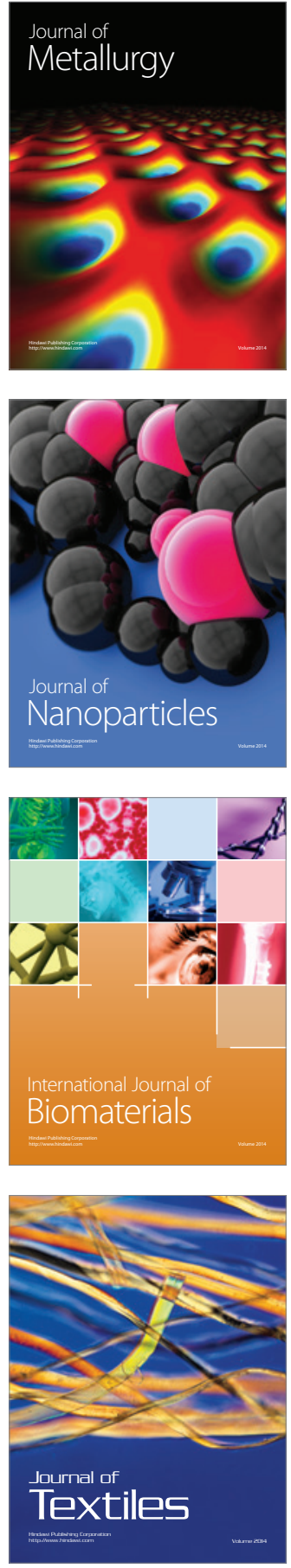